International Journal of Engineering \& Technology, $7(2.32)(2018) 397-399$
International Journal of Engineering \& Technology
SPC
Website: www.sciencepubco.com/index.php/IJET
Research paper

\title{
Internet of Things on Smart Villages
}

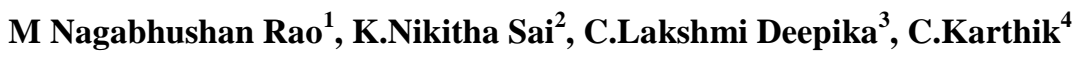 \\ ${ }^{1,2,3,4}$ Dept of CSE , K L E F,Vaddeswaram, India \\ *Corresponding author E-mail: ${ }^{1}$ mnraosir@gmail.com
}

\begin{abstract}
The idea of internet of things plays an important role in the development of future technology. IOT is the basic vision for the future success growth in finding the new technologies. The logical basis for a course of action behind the IOT working is the result of combining or uniting all the sources of communication technologies. All the devices which are present in the system are made to function with each other, just to perform their job in a balanced manner. Due to the increase in population, it lets the city and villages to facilitate and function in a better and smarter way. Therefore, above lines put together a reason for the invention of idea of smart cities. For this to work, these cities performed two different functions. First function is all about only fetching the information from both sensors and other remote devices. Second function analyzes the information which is observed from the above function and appropriate actions are made. This paper explains the idea about smart villages, it is focused completely on villages to study them and then provide the solution for those affected areas. It also helps in the improvement of their quality of life.
\end{abstract}

Keywords:IOT,Sensors, RFID,WSN,Smart Villages..

\section{Introduction}

The IOT have the capability of describing world wide network of some trillions of objects which are actually collected from the world wide physical environment, that can be spread or promote widely by the internet and are transmitted to the end users finally. Users can connect with these smart objects by internet and can make queries for needed. Their objective is to generate a wide network which contains of different smart devices which facilitate data of sharing about the worldwide things at anywhere and time easily. Internet of things will lead in the fore coming technology in communications.it plays the main role in the concept of idea of smart cities and villages. It allows all the components which are in the system to act in smarter terms for smooth functioning of the system by interaction and coordination with each other. These items are associated through the remote system. The said devices will be appended with clever decision making parts. There are diverse advancements which are utilized as a part of IOT which are named as RFID, Cloud Computing and so on. RFID is determined as the Radio Frequency Identification. It's really doled out to identify labels with different items . At that point these labels will transmit the data which is as of now read by RSID reader and it will be utilized by the necessity. These labels at that point transform the typical items into intelligent devices. Indeed, even the Sensors assume a principle part in IOT in which they are utilized to gather and interfere with the information from different assets. The 3s innovation mostly comprises of Global Position System both Geography Information System and Remote Sense play an important role in telling about the whereabouts of the diverse devices by utilizing some kind of sensors and satellites and so forth lastly process that data. Also Wireless Sensor Network(WSN) are used to transmit the data in IOT. Cloud administrations gives systems and assets to data warehousing and calculation which are incorporated into the WSN. The cloud services are basically loca- tion independent. These services are supplied immediately when they are required and this can be done easily. The technology of internet of things has created the concept of smart cities. This concept is offering a neat and efficient way to implement the technology of IOT by introducing this technology particularly in all categories of jobs of modern cities in the day to day life. The devices like computer and mobiles are connected conventionally by the internet. similarly, internet of things connect all the possible devices which in turns as a smart device I.e tag as a smart device. These devices which are stated above will interact among themselves and do the operations accordingly. In country like japan the devices are mainly used to interrelate each other through out the internet. Similarly, developing country like India where there is a rise in a population, due to this the necessity had grown up for the use of available resources in the best possible manner. The more efficient usage of resources had made the demands increasing, this is the reason why internet of things became the savior.

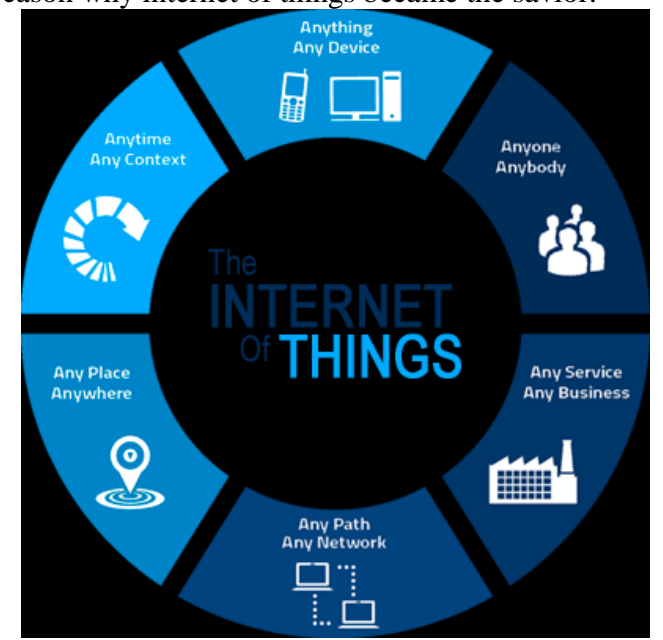




\section{The Main Idea of Smart Villages}

The proportion of the people who live in cities is very large. So the researches and the governments put their best effort and also helping for the better development of smart cities in both ways like self sustainable and advanced technology. These cities are able to use these devices in a smart way. The same implementation can also be drawn -out to the concept of villages. In India there is a population which consists of farming based economy, in this rural population maintains a good proportion. Compared with life of city counter parts, the life of villages will be more difficult There is a heavy necessity in improving the quality of life in villages and cities. Some ideas of the smart cities are useful in implementing the life of rural areas. For instance we can use digital cameras and sensordevices for the surveillance on the roads and some another sensors for rest of the sectors like agriculture, health care, electrical appliances and house appliances etc, and all other devices which can be used for smart living. In the above stated sections in the villages, the problems are taken into consideration and analyse them according to the revised problem and finally found the solution to implement them by using the idea of internet of things of smart villages. Like this villages can be changed into smart villages model. Now here we need to design the smart village model. In this the first step includes the recognition of all devices that need to communicate with each other and work simultaneously. Once the first step is done then the large amount of switches, sensors, buttons and surveillance cameras will be installed along with some fixed devices for emergency purposes. Both sensors and devices connect each other and start producing the large amount of data which is finally stored and processed on the cloud servers. There is a concept called big data analytics in which it consists of tools like Hadoop analyzes the data for the finest usage. The main goal of the idea of IOT on smart villages is to achieve smart homes, smart agriculture, smart education, smart weather systems, surveillance systems and likewise many others.

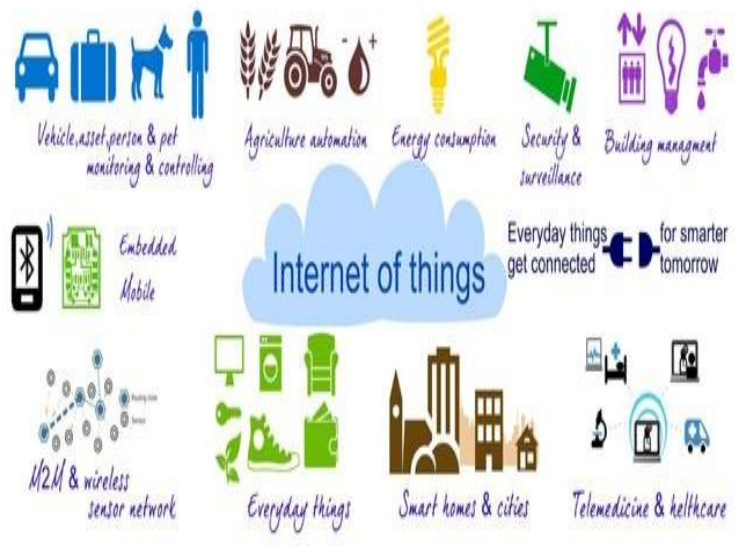

\subsection{Smart Buildings}

The usage of cameras and sensors can achieve the smart homes and smart buildings. Due to this usage they can analyze the necessary actions which are to be implemented later, by the real time data which are produced by the sensors and cameras. For example, smoke sensors which are installed at home can detect the smoke which is produced and automatically water will be sprinkled in that particular area to stop or to combat fire. Not only this even there are many more sensors which are very helpful. Similarly, electric sensors can switch off the lights when they are not in use in both home and buildings. These can be monitored automatically. As there is no electricity continuously in the village so, energy management plays an important role efficiently in this concept. In the case of any anomalies or risks these cameras which are installed can be keep on monitoring the buildings and alerts are generated automatically once the risk is detected. These sensors are useful whenever security is needed. There are different sensors are also available based on water tanks. Once the sensor is kept inside the water tank, it will measure the water level and pressure level and check whether the water tank is filled or not. If it is not filled automatically this sensor fill ups the water according to the size of the water tank. Faults of the water pipes or if any damages are occurred for the water tank, then it can be sensed automatically.

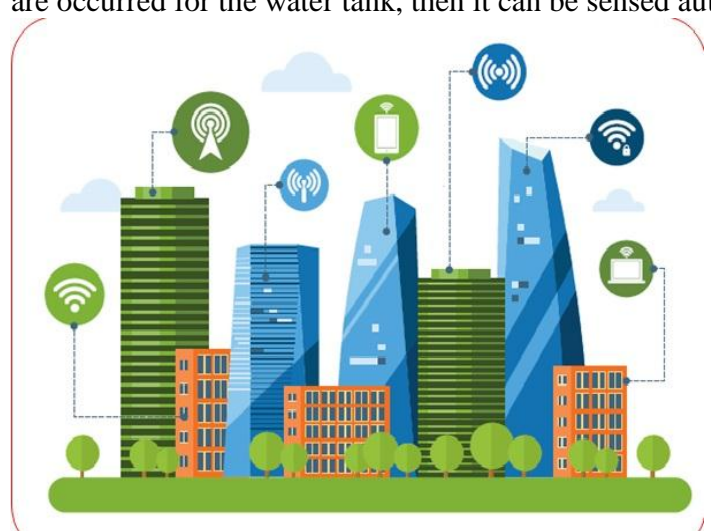

\subsection{Smart Weather and Irrigation}

Perfect weather forecasts will be gratefully useful in the villages so that they can grow their crops according to the information produced. As we already know most of the people in villages are working in the field of agriculture for their living. Environmental sensors are used for the farmers in giving the information about the weather forecasting about which field should be grown according to the season. These environment sensors will take the villages to the large extent based on the farming. Irrigation, sowing, and harvesting are the main activities which are under farming are now presently depending on weather forecasting. Particularly in the field of farming the smart irrigation system, the sensors are used. The optimal use of water resources can be ensured by the data of remote satellite.

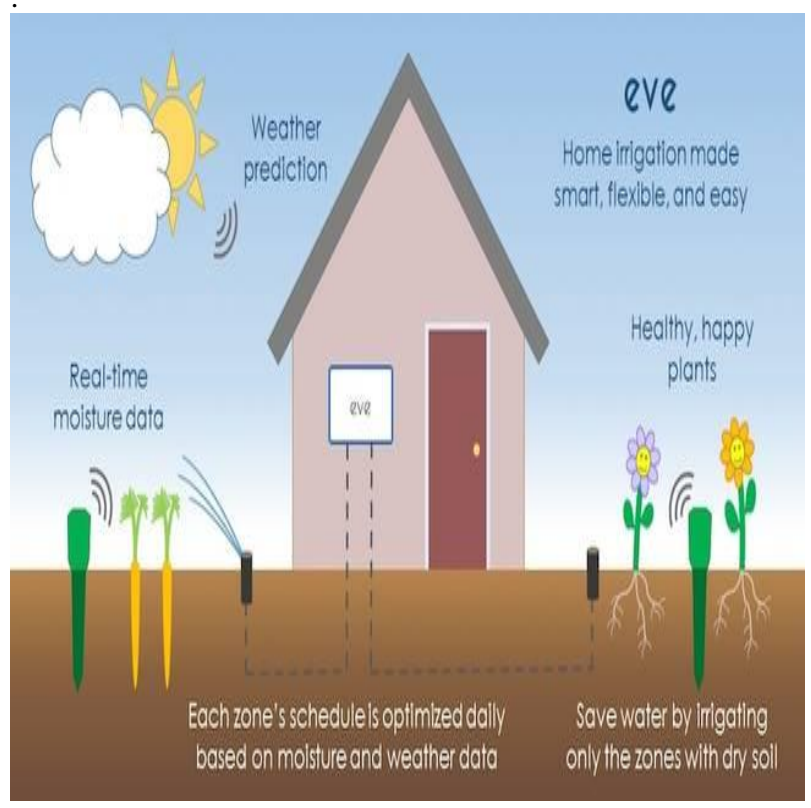

\subsection{Smart Farming}

Agriculture being the most important occupation of all rural areas, the people who do farming have to get the greatest profit out from the system of internet of things and Smart villages. We have to include tracking of how and where the efforts are being placed. Everything can be tracked and made better using data from all the 
sources we have. There are many such people who are involved in the whole process. Sensors that are set up in the farming lands will help the farming people to know about the selection of crop to be laid, the amount of crop that could produce by knowing about the type of grounds or weather, the amount of water required by the usage of smart drip-based irrigation systems, which fertilizer to be applied based on the soil type etc.

\subsection{Smart Diary}

In general, Dairy Farming is considered to be the second most important occupation of a farmer. The use of the sensors and cameras favor a lot for easy and better administration of their work. Sudden emergencies and any change that need to done can be reported immediately and the solution can be fetched instantly. It also helps in the maintenance of correct temperature levels for the animals to be maintained. The amount of food, water and other components for the cattle can be taken care of. The use of such smart technologies will make it easy for the people as all the things are done automatically by the devices and do not need any human intervention.

\section{Conclusion}

The idea of smart villages was considered to as a very advanced and complex thing but now it has become a reality. The whole credit of the progress is due to the evolving technology that has been put into field. IOT combines the benefits of multiple technologies that are into picture and gives the output of intelligent and smart devices in a city. The at most of use of such kind of technologies are observed in villages, where they tend to do invest a lot of hard work and time which could even be done in their absence by the smart technologies that are been into ground. We have also done research in many other areas related to Internet Of Things and have given suggestions accordingly.

\section{References}

[1] http://www.irdindia.in/journal_ijraet/pdf/vol5_iss6/1.pdf

[2] https://www.irjet.net/archives/V3/i5/IRJET-V3I535.pdf

[3] http://www.ijettjournal.org/2016/volume-32/number-6/IJETTV32P259.pdf

[4] https://www.ijser.org/researchpaper/Study-and-development-ofvillage-as-a-smart-village.pdf

[5] http://www.irdindia.in/journal_ijraet/pdf/vol5_iss6/1.pdf

[6] http://ipasj.org/IIJIT/Volume3Issue7/IIJIT-2015-07-10-2.pdf

[7] http://drona.csa.iisc.ac.in/ nv/95DesignofSmartVillages-IISc.pdf 